\title{
Mitochondrial ATPase in the gills of the shore crab Carcinus maenas
}

\author{
D. Siebers ${ }^{1}$, J. Hentschel ${ }^{2}$, K. Böttcher ${ }^{1} \&$ C. Lucu $^{3}$ \\ ${ }^{1}$ Biologische Anstalt Helgoland; Notkestr. 31, D-W-2000 Hamburg 52, Federal Republic \\ of Germany \\ ${ }^{2}$ Universität Konstanz, Fakultät für Biologie; Universitätsstr. 10, D-W-7750 Konstanz 1, \\ Federal Republic of Germany \\ ${ }^{3}$ Ruder Boskovic Institute, Center for Marine Research; 52210 Rovinj, Croatia
}

\begin{abstract}
Posterior gills (No.7 and 8) of shore crabs Carcinus maenas were homogenized and fractionated by means of differential and density gradient centrifugation. Employment of marker enzymes Na-K-ATPase and carbonic anhydrase for plasma membranes and cytochrome oxidase for mitochondria showed that these structural elements were separated. Ultramicroscopic investigations of combined fractions confirmed the presence of the respective mitochondrial and vesicular plasma membrane structures. An ATPase which did not depend on the presence of sodium $(20 \mathrm{mM})$ ions in the incubation medium but on the presence of potassium $(20 \mathrm{mM})$ ions only was found in the mitochondrial fractions. The mitochondrial ATPase was tightly bound to cellular particulates and activated approximately threefold by bicarbonate $(20 \mathrm{mM})$ ions. The activity of this ATPase was nearly completely inhibited by oligomycin $\left(1 \mu \mathrm{g} \mathrm{ml}^{-1}\right)$ and greatly inhibited by low levels $(5 \mathrm{mM})$ of thiocyanate and calcium ions, the $\mathrm{K}_{\mathrm{i}}$ for $\mathrm{Ca}^{2+}$ being ca $4 \mathrm{mM}$. The results obtained confirm literature data on high mitochondrial densities in crab gills and allow the assumption of significant rates of energy metabolism in these organs. Considering its properties the mitochondrial ATPase is clearly distinct from crab gill Na-K-ATPase and can be measured specifically in samples containing Na-KATPase. Mitochondrial ATPase is therefore considered a suitable and reliable marker enzyme for mitochondria.
\end{abstract}

\section{INTRODUCTION}

Crustacean gills are multifunctional organs located in the interphase between the animal and its environment. While particulate food is processed through the alimentary canals, and volume regulatory bulk water is released through the renal organs (Oglesby, 1981), the gills are the main sites of exchanges of respiratory gases (Burnett \& McMahon, 1985; Böttcher et al., 1991), osmo- and ionoregulatory active ion uptake (Kirschner, 1979; Towle, 1981; Lucu, 1990), regulation of the acid-base status of the hemolymph (Truchot, 1979; Perry \& Laurent, 1990) and excretion of nitrogenous metabolic end products (Kormanik \& Cameron, 1981). All these functions have in common their participation in the processes of biological transport, their location in membranous structures and their close biochemical and physiological interrelation.

Accordingly, the branchial cells show all the features known to be characteristic of transporting epithelia, i.e. dense networks of invaginated plasma membranes in the apical membranes and considerably more pronounced ones in basolateral membranes. In 
crustacean gills, the basolateral membranes are closely associated with high numbers of prolonged mitochondria. Mitochondrial densities and lengths become reduced in the regions beneath the apical membrane layers; while apical membranes themselves are seemingly not associated with mitochondria (Copeland \& Fitzjarrel, 1968; Goodman \& Cavey, 1990).

In contrast to the thoroughly investigated branchial ultrastructure and transport functions, especially those playing a role in energy-consuming osmoregulatory ion translocation, little is known about the energy providing processes of mitochondrial metabolism.

This publication describes the presence of mitochondrial ATPase in the gills of the shore crab Carcinus maenas including some properties of the enzyme and suggests its usefulness as a precisely measurable and reliable mitochondrial marker.

\section{MATERIALS AND METHODS}

\section{Crabs}

Shore crabs Carcinus maenas were obtained from fishermen at Kiel, Baltic Sea. Transport to the laboratory, maintenance, water quality, feeding and light conditions were identical to the procedures previously described (Siebers et al., 1983). Crabs were acclimated to a salinity of $10 \%$ for at least 1 month before experimental use. Experimentals were males of over $5 \mathrm{~cm}$ carapace width within the intermolt phase.

\section{Homogenate preparation and centrifugation procedures}

After removal of the carapace, the posterior gills (No. 7 and 8) were excised, blotted to near-dryness and weighed. $0.1 \mathrm{~g}$ tissue was homogenized for $45 \mathrm{sec}$ with $0.9 \mathrm{ml}$ TRIS/ EDTA buffer ( $0.25 \mathrm{M}$ sucrose, $0.02 \mathrm{M}$ TRIS, $0.002 \mathrm{M} \mathrm{Na}_{2}$-EDTA, pH 7.6) with a teflonglass Potter-Elvehjem homogenizer at $400 \mathrm{rev} \cdot \mathrm{min}^{-1}$ and $0{ }^{\circ} \mathrm{C}$. Homogenates were then passed through $50 \mu \mathrm{m}$ surgical gauze.

In order to analyse the proportion of mitochondrial ATPase bound to cellular particulates, homogenates were centrifuged at $100,000 \mathrm{~g}$ for $1 \mathrm{~h}$ at $4{ }^{\circ} \mathrm{C}$ in an ultracentrifuge (L8-70 M, Beckman) with a $70.1 \mathrm{Ti}$ rotor. The supernatants (SI) were decanted, and the pellets (PI) were resuspended, rehomogenized and centrifuged again to obtain supernatants SII and pellets PII. This procedure was repeated a third time (see Fig. 1). A second approach was performed in the same way except that the resuspended and rehomogenized pellets were additionally ultra-sonicated twice for $5 \mathrm{sec}$ at $60 \mathrm{~W}$ with a pause of $10 \mathrm{sec}$ (sonicator type GTS22/125, Sonotrode Tu 157/4; KLN Ultraschall, Heppenheim, FRG).

Subcellular components were fractionated by means of density gradient centrifugation. Homogenates were centrifuged at $750 \mathrm{~g}$ for $20 \mathrm{~min}$ at $4{ }^{\circ} \mathrm{C}$. The resulting supernatant was stored and the pellet resuspended, rehomogenized and centrifuged again. The second pellet was discarded. The combined $750 \mathrm{~g}$ supernatants were centrifuged at $7500 \mathrm{~g}$, the pellet was resuspended and placed on top of a $33.5 \mathrm{ml}$ continuous sucrose gradient $(10-40 \%, w / w)$. Sucrose was dissolved in homogenizing medium. The gradient was centrifuged at $100,000 \mathrm{~g}$ for $1.5 \mathrm{~h}$ in a Beckman rotor SW 27. By means of a capillary 


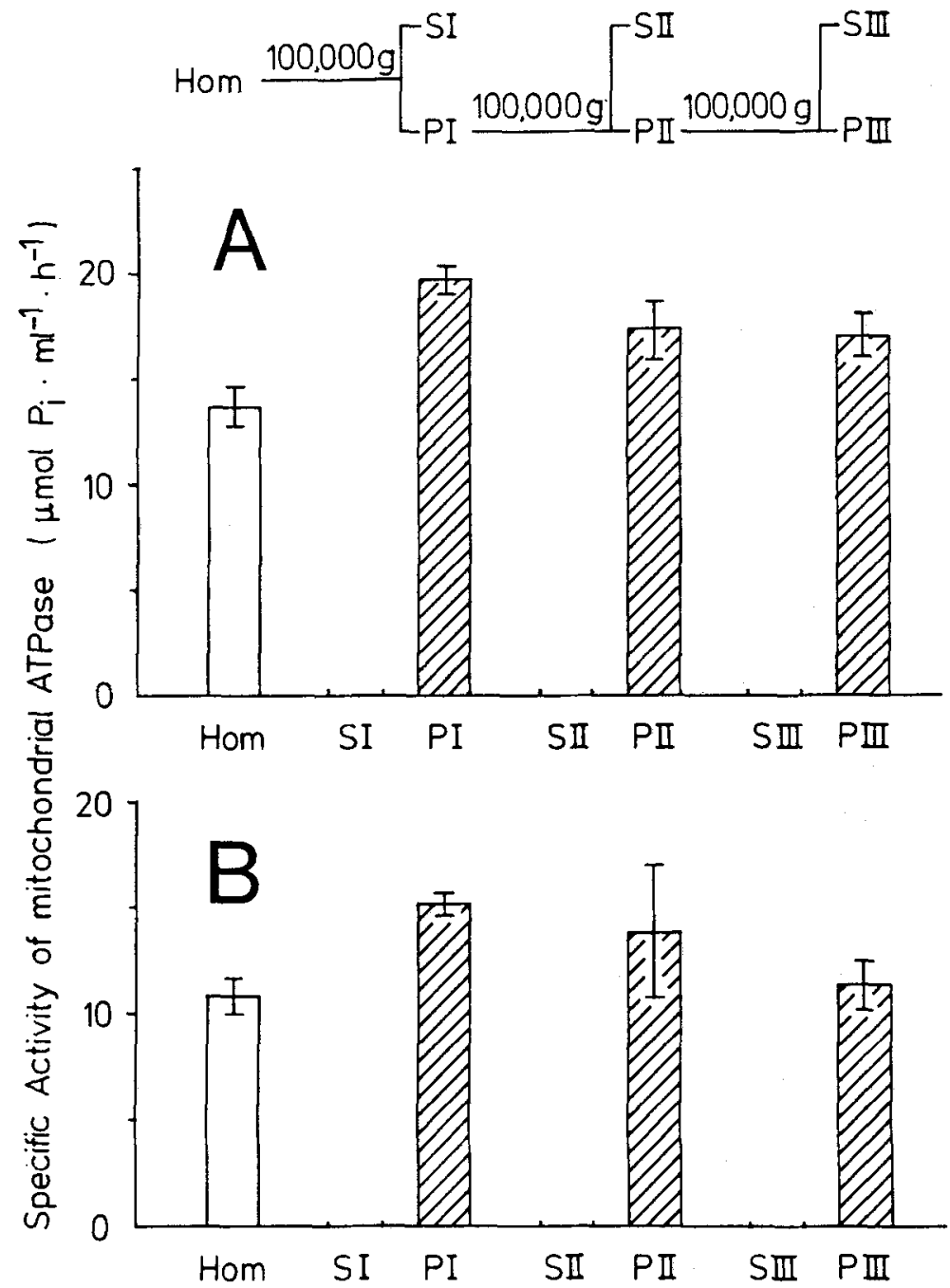

Fig. 1. Carcinus maenas. Mitochondrial ATPase in homogenates, supernatants (SI-SIII) and resuspended and rehomogenized pellets (PI-PIII) of one or repeated $100,000 \mathrm{~g}$ centrifugations. In the second and third centrifugation, resuspended and rehomogenized pellets of the previous centrifugation were used (A). Resuspended and rehomogenized pellets were additionally ultrasonicated and centrifuged again (B). Mitochondrial ATPase activities were calculated from the differences between the total ATPase activities and activities measured in the presence of $1 \mu \mathrm{g} \cdot \mathrm{ml}^{-1}$ oligomycin. Non-specific (oligomycin-insensitive) activities were always less than $5 \%$ of total activities. Bars represent means \pm s.d. obtained from a sample size of 6 gills

tube immersed to the bottom of the centrifuge vial, 30 fractions of approx. $1.3 \mathrm{ml}$ were withdrawn using a peristaltic pump and transferred to a fraction collector. Prior to further analysis the fractions were stored at $-70^{\circ} \mathrm{C}$ for no longer than 1 week. 


\section{Determinations of marker enzymes, mitochondrial ATPase and protein}

$\mathrm{Na}-\mathrm{K}-\mathrm{ATP}$ ase present in homogenates and in the fractions of the density gradient was measured spectrophotometrically by monitoring the absorbance at $340 \mathrm{~nm}$ in a coupled assay using the modified procedure of Siebers et al. (1982). The final test volume of $1.3 \mathrm{ml}, \mathrm{pH} 7.25$ consisted of $0.1 \mathrm{M}$ imidazole/HCl, $75 \mathrm{mM} \mathrm{NaCl}, 64 \mathrm{mM} \mathrm{NH}_{4} \mathrm{Cl}, 5 \mathrm{mM}$ $\mathrm{MgCl}_{2}, 5 \mathrm{mM}$ ATP-Na $\mathrm{Na}_{2}, 2 \mathrm{mM}$ phosphoenolpyruvate (PEP), $0.33 \mathrm{mM} \mathrm{NADH}-\mathrm{Na}_{2}, 12.2 \mathrm{U}$. $\mathrm{ml}^{-1}$ lactate dehydrogenase (LDH) and $0.36 \mathrm{U} \cdot \mathrm{ml}^{-1}$ pyruvate kinase (PK). LDH and PK were suspended in 3.2 M ammonium sulfate. Assays were performed in the absence and presence of $5 \cdot 10^{-4} \mathrm{M}$ ouabain which specifically and completely inhibits Na-K-ATPase. The reduction of total ATPase activity due to the presence of ouabain thus represents NaK-ATPase activity.

Mitochondrial ATPase was measured in supernatants and pellets obtained by repeated $100,000 \mathrm{~g}$ centrifugations and in the fractions of the sucrose density gradient in a comparable coupled assay $\left(340 \mathrm{~nm}, 25^{\circ} \mathrm{C}\right)$. The final volume was $1.3 \mathrm{ml}$ consisting of $50 \mathrm{mM}$ HEPES, $30 \mathrm{mM}$ TRIS, $100 \mathrm{mM} \mathrm{KCl}, 3 \mathrm{mM} \mathrm{MgCl}_{2}, 3 \mathrm{mM}$ TRIS-ATP (Commercial TRIS-ATP or TRIS-ATP prepared from $\mathrm{Ba}^{2+}$-ATP with TRIS/ $\left.\mathrm{H}_{2} \mathrm{SO}_{4}\right), 2 \mathrm{mM} \mathrm{PEP}, 0.33 \mathrm{mM}$ $\mathrm{NADH}-\mathrm{Na}_{2}, 12.2 \mathrm{U} \cdot \mathrm{ml}^{-1} \mathrm{LDH}, 0.36 \mathrm{U} \cdot \mathrm{ml}^{-1} \mathrm{PK}$. LDH and PK were suspended in $50 \%$ glycerol. When oligomycin - an antibiotic specifically directed against mitochondrial ATPase (Lardy et al., 1975) - was applied in order to determine non-specific activities the assays including controls contained $0.5 \%$ ethanol (supplied under agitation from a stock solution of oligomycin dissolved in pure ethanol), a concentration not affecting ATPase activity.

Activity of carbonic anhydrase (CA) was determined by the phenol red indicator method published by Maren (1960) and modified according to Bruns et al. (1986). Activity (A) of the enzyme was calculated by comparing the uncatalyzed reaction time $\left(t_{o}\right)$ measured in seconds with the catalyzed reaction time $\left(t_{\text {enz }}\right)$ according to the following equation:

$$
\mathrm{A}=\mathrm{t}_{\mathrm{o}} / \mathrm{t}_{\mathrm{enz}}-1
$$

Following the proposal by Maren (1954), 1 unit of CA activity was defined as the concentration of enzyme in the final assay volume required to halve the uncatalyzed reaction time.

Activity of cytochrome oxidase was determined by monitoring the oxidation of reduced cytochrome $\mathrm{c}$ at $550 \mathrm{~nm}$ (according to Wharton \& Tzagoloff, 1967). Protein concentrations were analysed by means of a commercial assay (BCA-assay, Pierce).

Analytical grade inorganic salts, HEPES and imidazole were purchased from Merck (Darmstadt), NADH, LDH and PK, and Na-pyruvate from Boehringer (Mannheim) and oligomycin from Serva (Heidelberg). TRIS, sucrose, ATP $\left(\mathrm{Ba}^{2-}-\right.$, TRIS-, and $\mathrm{Na}^{+}$-salt), PEP, and cytochrome $c$ were purchased from Sigma (München).

\section{Transmission electron microscopy}

For electron microscopy the non-overlapping fractions obtained by density gradient centrifugation containing mitochondria (fractions 2-6, see Fig. 2) and plasma membranes (fractions 13-17) were fixed in $0.05 \mathrm{M} \mathrm{Na}$-cacodylate buffered with $4 \%$ glutaraldehyde, $400 \mathrm{mOsm} \cdot \mathrm{kg}^{-1}, \mathrm{pH} 7.3$, by mixing identical volumes of suspensions of the gradient with 


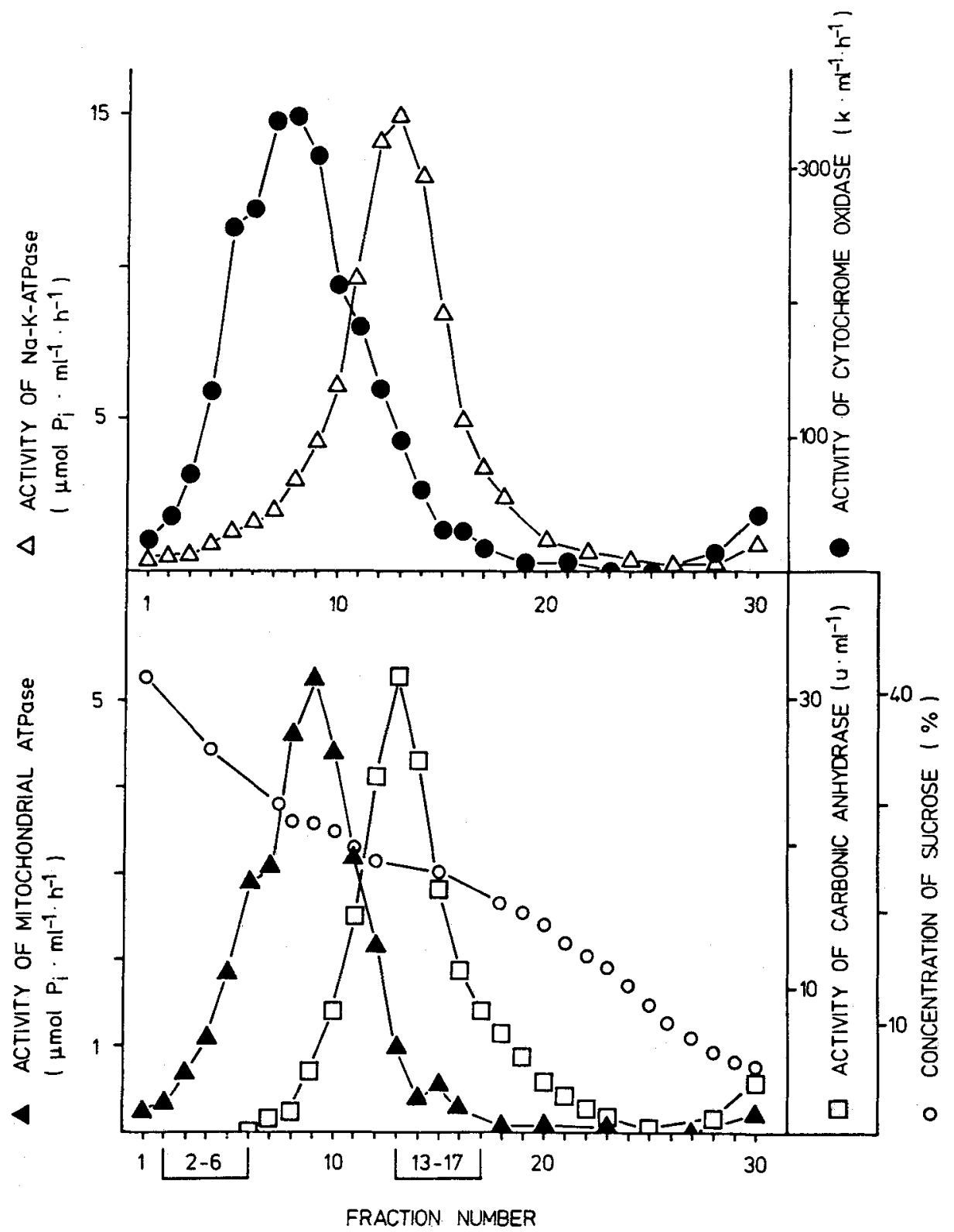

Fig. 2. Carcinus maenas. Fractionation of subcellular particulates of gill tissue by density gradient centrifugation. A homogenate prepared from posterior gills was centrifuged at $750 \mathrm{~g}$. The supernatant was centrifuged at $7500 \mathrm{~g}$, and the resuspended pellet was layered on top of a $10-40 \%$ (w/w) continuous sucrose density gradient which was centrifuged for $1.5 \mathrm{~h}$ at $100,000 \mathrm{~g}\left(4^{\circ} \mathrm{C}\right)$. Following centrifugation, 30 fractions were collected. Cytochrome oxidase and $\mathrm{K}^{+}$-dependent ATPase are characteristic of mitochondria; Na-K-ATPase and carbonic anhydrase are plasma membrane mar- 
the fixative to make up a final concentration of $2 \%$ glutaraldehyde $(1 \mathrm{~h}$, room temperature). After centrifugation $\left(55,000 \mathrm{~g}, 4{ }^{\circ} \mathrm{C}, 45 \mathrm{~min}\right)$ the pellets were resuspended in the initial volumes of washing buffer ( $\mathrm{Na}$-cacodylate) and stored at $4{ }^{\circ} \mathrm{C}$. Samples were postfixed in $2 \%$ osmium tetroxide $\left(1 \mathrm{~h}, 4{ }^{\circ} \mathrm{C}, \mathrm{pH} 7.3\right)$ and dehydrated in an ascending series of alcohol up to $70 \%$ ethanol. Specimens were then contrasted overnight with $1 \%$ phosphotungstic acid and $1 \%$ uranylacetate in $70 \%$ ethanol, completely dehydrated and embedded in Epon 812. Ultrathin sections were cut using a Reichert ultracut $E_{1}$ stained with lead citrate and viewed in a Siemens CT 150 TEM.

\section{RESULTS}

\section{Mitochondrial localization of the $\mathrm{K}^{+}$-dependent ATPase activity}

Samples of crude homogenates were tested for ATPase activity in the presence of $100 \mathrm{mM} \mathrm{KCl}$ using the assay conditions presented in "Materials and Methods" for mitochondrial ATPase (Fig. 1). The activities measured amounted to $14.3 \pm 1.0$ (A) and $11.1 \pm 1.0(\mathrm{~B}) \mu \mathrm{mol} \mathrm{P}_{\mathrm{i}} \cdot \mathrm{ml}^{-1}$ homogenate $\cdot \mathrm{h}^{-1}$. After $100,000 \mathrm{~g}$ centrifugations, once or up to twice repeated, of the resuspended and rehomogenized (A) or additionally ultrasonicated pellets (PI-PIII) (B), no activity could be detected in the supernatants (SI-SIII) (Fig. $1 \mathrm{~A}$ and $\mathrm{B})$. For repeated centrifugations the previous pellet was resuspended each time in the original volume of the homogenate. Since concentrations of total proteins in the resuspended pellets were reduced with regard to homogenates as a result of lacking dissolved proteins contained in the supernatants activities are presented on a "per $\mathrm{ml}$ basis". Therefore, the activities of supernatants and pellets shown in Figure 1 can be directly compared. The results obtained imply that the ATPase, which is active in the absence of sodium but in the presence of $100 \mathrm{mM} \mathrm{KCl}$, is bound very tightly to cellular particulates spun down at $100,000 \mathrm{~g}$. Even strong mechanical handling of the samples such as repeated resuspension, recentrifugation and ultrasonication of the pelleted material did not bring detectable proportions into solution.

In order to find out the subcellular localization of the branchial $\mathrm{K}^{+}$-dependent ATPase, centrifugation $(100,000 \mathrm{~g}, 1.5 \mathrm{~h})$ of a $7500 \mathrm{~g}$ pellet in a continuous sucrose gradient $(10-40 \%, w / w)$ was used. Thirty fractions obtained after centrifuging the gradient were analysed for mitochondrial and plasma membrane marker enzymes. As shown in Figure 2, the fractions containing the mitochondrial marker cytochrome oxidase were clearly separated from the fractions containing the markers for plasma membranes, $\mathrm{Na}-\mathrm{K}-\mathrm{ATP}$ ase and carbonic anhydrase, though there was a zone of overlap. The ATPase characterized by $\mathrm{Na}^{+}$-independence but $\mathrm{K}^{+}$-dependence was present in the mitochondrial fractions and has thus to be considered as mitochondrial ATPase.

The structural equivalents of the marker enzymes analysed in the fractions of the sucrose density gradient was shown by transmission ultramicroscopy. Fractions 2-6 and 13-17. (see Fig. 2) were combined and prepared for TEM analysis as detailed in the "Materials and Methods" section. The fractions used for TEM analysis were selected within the zones of the gradient with minimal overlap, anticipating nearly pure mitochondria in fractions 2-6 and plasma membranes in fractions 13-17 uncontaminated by mitochondria. As shown in Figure 3, mitochondria (upper photo) contained only a few plasma membrane elements and were clearly discernible from a relatively pure fraction 


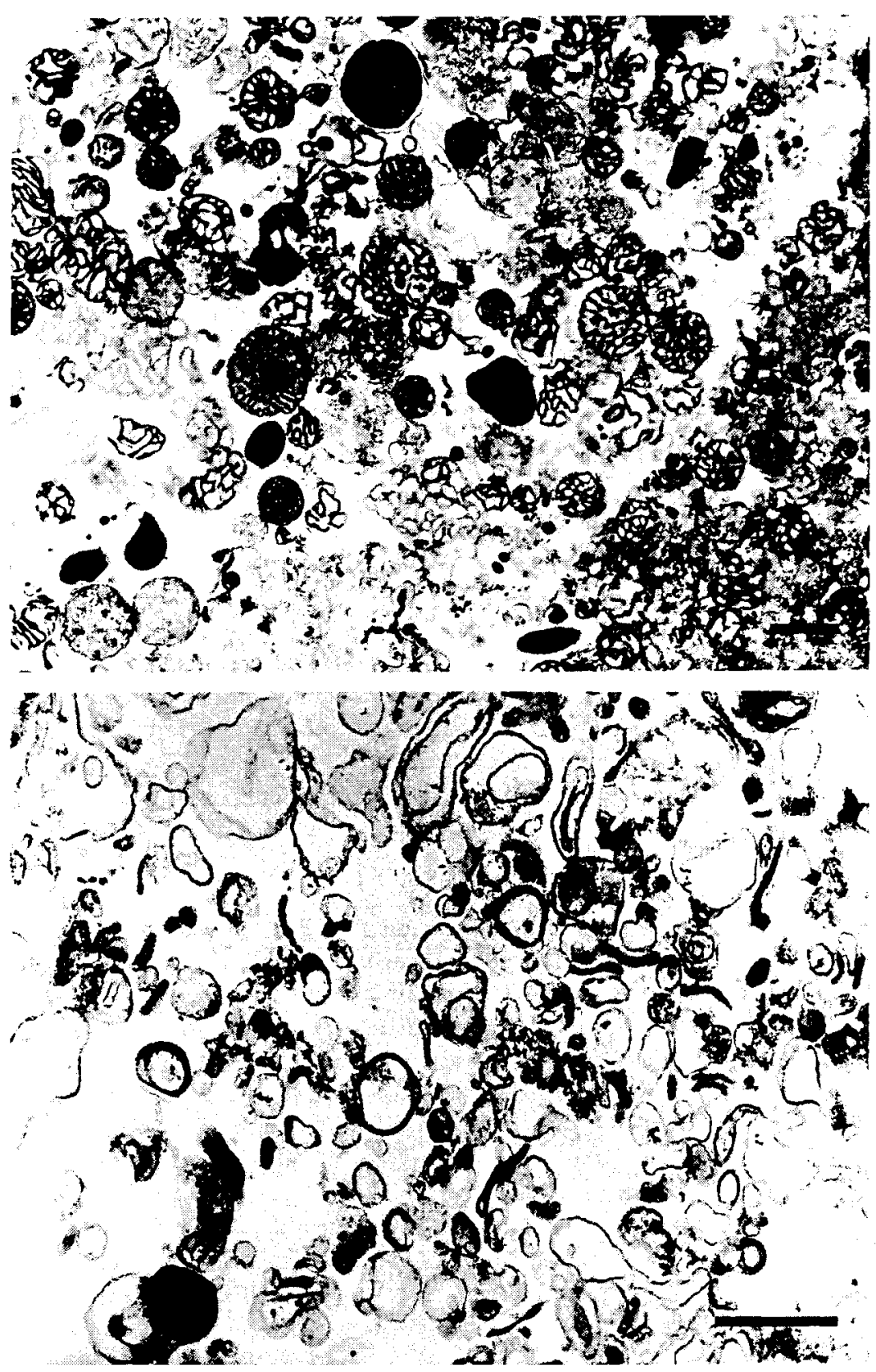

Fig. 3. Carcinus maenas. Electron micrographs of mitochondrial fractions 2-6 (upper photo) and plasma membrane fractions 13-17 (lower photo) obtained by density gradient centrifugation. The fractions were obtained in the same way as detailed in the legend to Fig. 2. Mitochondrial and plasma membrane fractions were pooled, fixed, stained, cut into ultrathin sections as outlined under "Materials and Methods", and viewed in a Siemens CT 150 transmission electron microscope. The horizontal bars amount to $0.5 \mu \mathrm{m}$ 
of vesiculating plasma membranes (lower photo). Some mitochondria showed structural damage which could not be prevented by varying the osmolalities of the fixation solutions. The damage is therefore not considered to be a result of unphysiological osmolalities but - as discussed by Graszynski (1970) - rather reflects the sensitivity of crustacean mitochondria to mechanical handling. A comparable shape of mitochondria in the gills of the chinese crab Eriocheir sinensis has been described in the publication by Péqueux et al. (1983).

\section{Properties of mitochondrial ATPase}

The pure mitochondrial fractions 2-6 (Fig. 2) obtained from the sucrose density gradient were used to analyse some properties of mitochondrial ATPase. As shown in Figure 4, activity amounted to only $1.5 \mu \mathrm{mol} \mathrm{P}_{\mathrm{i}} \cdot \mathrm{mg}^{-1}$ mitochondrial protein $\cdot \mathrm{h}^{-1}$ in the presence of $20 \mathrm{mM} \mathrm{NaCl}$ and was enhanced to reach values of ca $20 \mu \mathrm{mol} \mathrm{P}_{\mathrm{i}} \cdot \mathrm{mg}^{-1}$ protein $\cdot \mathrm{h}^{-1}$ when $20 \mathrm{mM} \mathrm{KCl}$ was employed in the incubation medium instead of $\mathrm{NaCl}$. This finding shows that the activity of mitochondrial ATPase clearly depends on the cationic milieu of the incubation medium. When $\mathrm{KCl}$ was replaced by $\mathrm{KHCO}_{3}$, activity was further greatly increased to levels of ca $70 \mu \mathrm{mol} \mathrm{P}_{\mathrm{i}} \cdot \mathrm{mg}^{-1} \cdot \mathrm{h}^{-1}$. Activities measured in the presence of $\mathrm{NaCl}$ and $\mathrm{KCl}$ imply that anions are not essential in determining enzymatic rates; however, $\mathrm{HCO}_{3}{ }^{-}$anions are obviously strong activators.

Activities were inhibited greatly in the presence of additional $5 \mathrm{mM} \mathrm{SCN}^{-}$and nearly completely in the presence of $1 \mu \mathrm{g} \cdot \mathrm{ml}^{-1}$ oligomycin. Low concentrations of calcium ions inhibited the activity of crab gill mitochondrial ATPase (Fig. 5), halving enzymatic rates in the presence of approximately $4 \mathrm{mM} \mathrm{Ca}^{2+}$.

\section{DISCUSSION}

The results obtained show that literature data on high densities of mitochondria in crab gills agree on the presence of a specific marker enzyme, the mitochondrial ATPase. The assays for this ATPase contained $0.66 \mathrm{mM} \mathrm{Na}^{+}$introduced by NADH-Na ${ }_{2}$. At these low levels of $\mathrm{Na}^{+}, \mathrm{Na}-\mathrm{K}$-ATPase activity was below its detection limit (Siebers et al., 1983). Using $1 \mu \mathrm{g} \cdot \mathrm{ml}^{-1}$ oligomycin, a specific inhibitor of mitochondrial ATPase, activities were reduced by more than $95 \%$. This result shows that under the conditions employed $\left(100 \mathrm{mM} \mathrm{KCl}, 0.66 \mathrm{mM} \mathrm{Na}^{+}\right.$and $1 \mu \mathrm{g} \cdot \mathrm{ml}^{-1}$ oligomycin in a parallel assay) oligomycin-sensitive ATPase can be measured specifically in samples containing high levels of Na-K-ATPase.

The activity of mitochondrial ATPase in posterior gills of shore crabs acclimated to brackish water of $10 \% \mathrm{~S}$ amounted to ca $13 \mu \mathrm{mol} P_{\mathrm{i}} \cdot \mathrm{ml}^{-1}$ homogenate $\cdot \mathrm{h}^{-1}$ (Fig. 1). Taking into consideration that $1 \mathrm{ml}$ homogenate contained $0.1 \mathrm{~g}$ tissue and that total protein concentrations were ca $25 \mathrm{mg} \cdot \mathrm{g}^{-1}$ fresh weight, the activity of mitochondrial ATPase on a protein basis is $5.2 \mu \mathrm{mol} \mathrm{P}_{\mathrm{i}} \cdot \mathrm{mg}^{-1}$ protein $\cdot \mathrm{h}^{-1}$. According to Siebers et al. (1982), activities of Na-K-ATPase in the posterior gills of crabs acclimatized to brackish water were approximately $11 \mu \mathrm{mol} \mathrm{P}_{\mathrm{i}} \cdot \mathrm{mg}^{-1}$ protein $\cdot \mathrm{h}^{-1}$. The activity of mitochondrial ATPase is thus $47 \%$ of the activity of Na-K-ATPase, a result indicating that both enzymes are present in the branchial tissues of shore crabs in comparable activities.

As outlined by Siebers et al. (1990), mitochondrial ATPase has previously been 


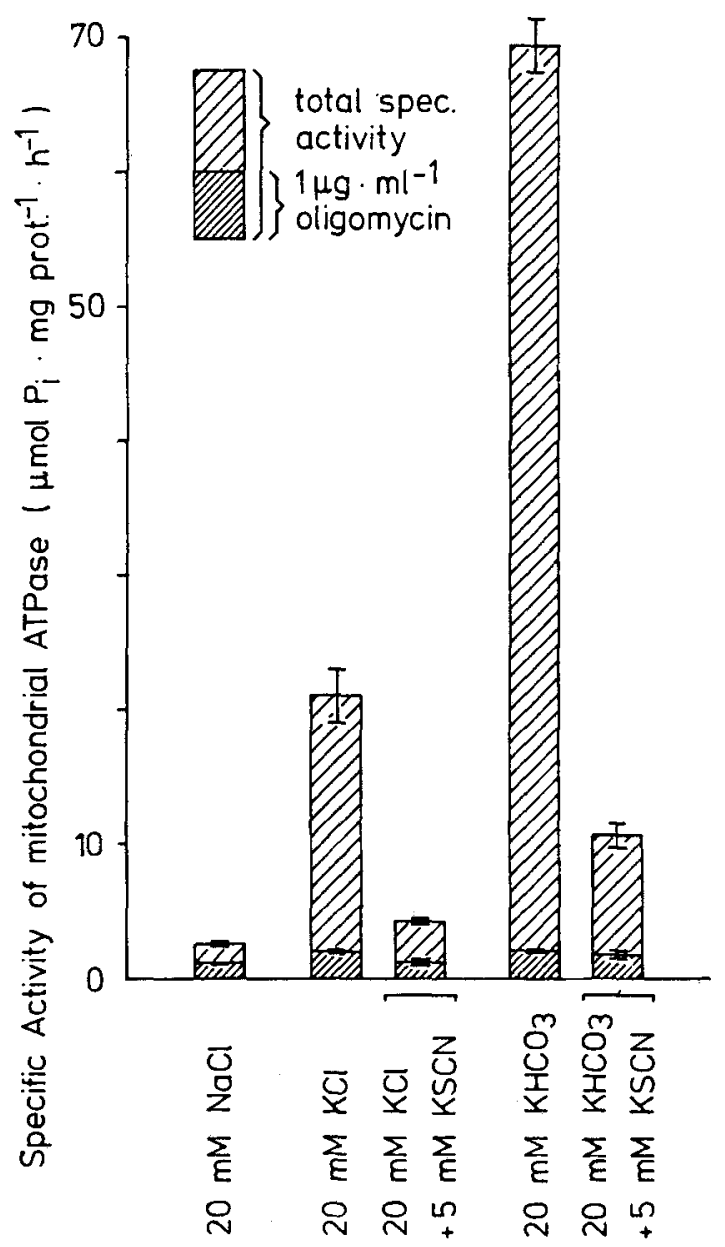

Fig. 4. Carcinus maenas. Properties of branchial mitochondrial ATPase. Samples of pooled mitochondrial fractions 2-6 (see Fig. 2 and upper photo, Fig. 3) obtained by density gradient centrifugation were analysed for ATPase activity. The fractions were obtained in the same way as detailed in the legend to Fig. 2. Activities were determined in the presence of $20 \mathrm{mM} \mathrm{NaCl}, \mathrm{KCl}$, or $\mathrm{KHCO}_{3}$ in absence and in the presence of $5 \mathrm{mM} \mathrm{KSCN}$ or $1 \mu \mathrm{g} \cdot \mathrm{ml}^{-1}$ oligomycin. Bars represent means \pm s.d. obtained from a sample size of $n=5$

considered as plasma membranous $\mathrm{Cl}^{-}$-ATPase located in the gills of fishes and crustaceans (see also Kirschner, 1979). In addition to the work published in 1990, the present paper describes the mitochondrial ATPase as being strictly bound to cellular particulates represented by the combined mitochondrial fractions uncontaminated with plasma membranes (Fig. 2). This work directly compares biochemical data of partially purified mitochondria with morphological structures. Mitochondrial localization was demonstrated by transmission electron microscopy of the respective pooled density gradient fractions. These purified mitochondrial fractions also served to analyse the enzyme's 


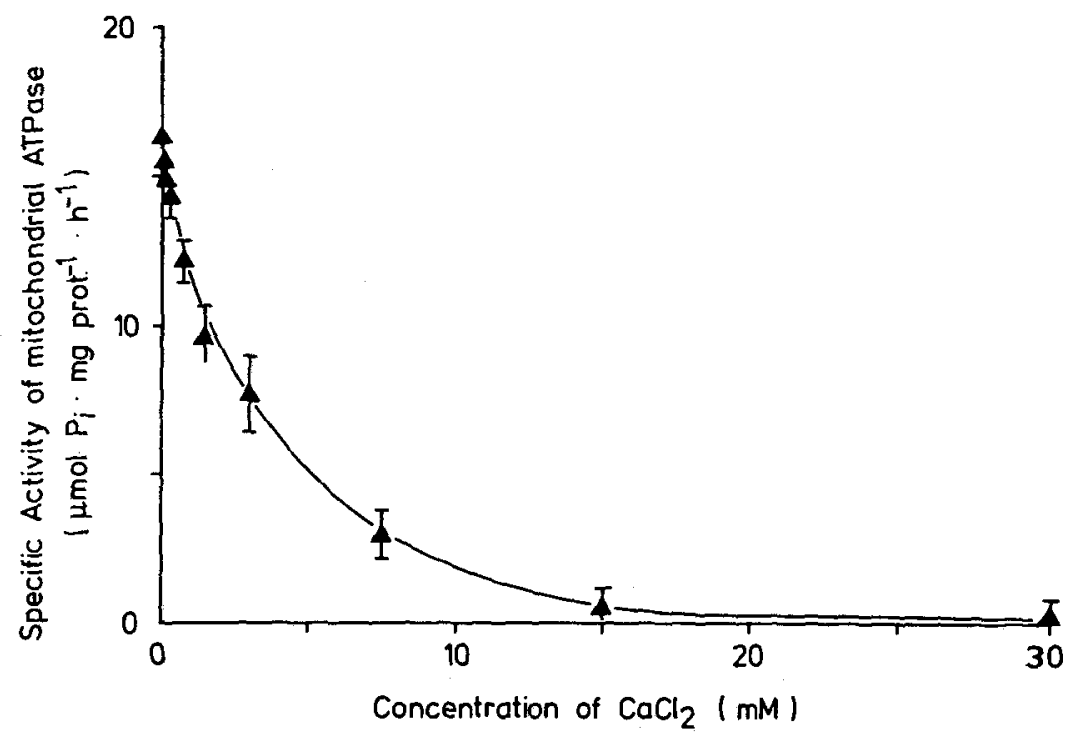

Fig. 5. Carcinus maenas. Inhibition of branchial mitochondrial ATPase by $\mathrm{Ca}^{2+}$ ions. Samples of pooled mitochondrial fractions 2-6 (see Fig. 2 and upper photo, Fig. 3) obtained by density gradient centrifugation were analysed for ATPase activity. The fractions were obtained in the same way as detailed in the legend to Fig. 2. Concentrations of $\mathrm{Ca}^{2+}$ ions varied between 0 and $30 \mathrm{mM}$. Activities were determined in the presence of $20 \mathrm{mM} \mathrm{KCl}$ and $1 \mu \mathrm{g} \cdot \mathrm{ml}^{-1}$ oligomycin. Bars represent means \pm s.d. obtained from a sample size of $n=5$

properties such as alkali ion dependence, bicarbonate activation and inhibition by calcium ions, thiocyanate and oligomycin. Besides other activators, anions with 3 oxygen atoms have been shown to increase the specific activity of mitochondrial ATPase, $\mathrm{HCO}_{3}{ }^{-}$, $\mathrm{HSO}_{3}{ }^{-}$and $\mathrm{HSeO}_{3}{ }^{-}$(Ebel \& Lardy, 1975). Published properties of mitochondrial ATPase thus correspond to the properties of the crab enzyme found in the mitochondrial fractions of the density gradient.

Susceptibility of activity of the partially purified enzyme to the presence of oligomycin and $\mathrm{Ca}^{2+}$ ions implies that the enzyme in question is the mitochondrial ATP synthase (Lardy et al., 1975). Since in crab gills the majority of mitochondria is embedded in the dense network of basolateral plasma membrane invaginations, the sites of ATP synthesis in mitochondria and ATP utilization by Na-K-ATPase present in plasma membranes are located in close vicinity. The relation between ATP synthesis and consumption was shown by Siebers et al. (1990) using crude gill homogenates. They found out that in posterior gills of shore crabs Carcinus maenas, the activities of both enzymes were increased greatly in osmoregulating specimens maintained in brackish water of $10 \% \mathrm{~S}$.

As both enzymes require different ionic milieus in their incubation media and as they are specifically inhibited by different antagonists (oligomycin and ouabain), they can be individually determined in the same sample. Therefore, the mitochondrial ATPase is considered as a reliable indicator of the presence of mitochondria and may thus be used as a mitochondrial marker enzyme. 
Acknowledgements. The authors want to thank G. Petrausch for skilful technical assistance, figure preparation and manuscript typing. Financial support of the work by the Deutsche Forschungsgemeinschaft (Si 295/2-1) is gratefully acknowledged.

\section{LITERATURE CITED}

Burnett, L. E. \& McMahon, B. R., 1985. Facilitation of $\mathrm{CO}_{2}$ excretion by carbonic anhydrase located in the surface of the basal membrane of crab gill epithelium. - Resp. Physiol, 62, 341-348.

Böttcher, K., Siebers, D., Becker, W. \& Petrausch, G., 1991. Physiological role of branchial carbonic anhydrase in the shore crab Carcinus maenas. - Mar. Biol. 110, 337-342.

Bruns, W., Dermietzel, R. \& Gros, G., 1986. Carbonic anhydrase in the sarcoplasmic reticulum of rabbit skeletal muscle. - J. Physiol. 371, 351-364.

Copeland, D.E. \& Fitzjarrel, A.T., 1968. The salt-absorbing cells in the gills of the blue crab (Callinectes sapidus Rathbun) with notes on modified mitochondria. - Z. Zellforsch. mikrosk. Anat. 92, 1-22.

Ebel, R.E. \& Lardy, H. A., 1975. Stimulation of rat liver mitochondrial adenosine triphosphatase by anions. - J. biol. Chem. 250, 191-196.

Goodman, S. H. \& Cavey, M. J., 1990. Organization of a phyllobranchiate gill from the green shore crab Carcinus maenas (Crustacea, Decapoda). - Cell Tissue Res. 260, 495-505.

Graszynski, K., 1970. Intrazelluläre Lokalisation von Enzymen des Flußkrebses. - Z. vergl. Physiol. $66,107-122$.

Kirschner, L. B., 1979. Control mechanisms in crustaceans and fishes. In: Mechanisms of osmoregulation in animals. Ed. by R. Gilles. Wiley, Chichester, 157-222.

Kormanik, G. A. \& Cameron, J. N., 1981. Ammonia excretion in animals that breath water: A review. - Mar. Biol. Lett. 2, 11-23.

Lardy, H., Reed, P. \& Chiu Lin, C.-H., 1975. Antibiotic inhibitors of mitochondrial ATP synthesis. Fedn Proc. Am. Socs exp. Biol. 34, 1707-1710.

Lucu, C., 1990. Ionic regulatory mechanisms in crustacean gill epithelia. - Comp. Biochem. Physiol. 97A, 297-306.

Maren, T.H., Ash, V.I. \& Bailey, Jr., 1954. Carbonic anhydrase inhibition. - Bull. Johns Hopkins Hosp. 95, 244-255.

Maren, T.H., 1960. A simplified micro method for the determination of carbonic anhydrase and its inhibitors. - J. Pharmac. exp. Ther. 130, 26-29.

Oglesby, L. C., 1981. Volume regulation in aquatic invertebrates. - J. exp. Zool. 215, $289-301$.

Péqueux, A., Chapelle, S., Wanson, S., Goffinet, G. \& Francois, C., 1983. $\left(\mathrm{Na}^{+}+\mathrm{K}^{+}\right)$ATPase activity and phospholipid content of various fractions of the posterior gills of Carcinus maenas and Eriocheir sinensis. - Mar. Biol. Lett. 4, 267-279.

Perry, S.F. \& Laurent, P., 1990. The role of carbonic anhydrase in carbon dioxide excretion, acidbase-balance and ionic regulation in aquatic gill breathers. In: Comparative Physiology. Ed. by R. K. H. Kinne, E. Kinne-Saffran \& K.W. Beyenbach. Karger, Basel, 2, 39-57.

Siebers, D., Leweck, K., Markus, H. \& Winkler, A., 1982. Sodium regulation in the shore crab Carcinus maenas as related to ambient salinity. - Mar. Biol. 69, 37-43.

Siebers, D., Winkler, A., Leweck, K. \& Madian, A., 1983. Regulation of sodium in the shore crab Carcinus maenas adapted to environments of constant and changing salinities. - Helgoländer Meeresunters. 36, 303-312.

Siebers, D., Petrausch, G. \& Böttcher, K., 1990. Is there a chloride ATPase in the gills of the shore crab Carcinus maenas? J. comp. Physiol. (B) 160, 223-231.

Towle, D.W., 1981. $\mathrm{Na}^{+}-\mathrm{K}^{+}$-ATPase in ionic regulation by marine and estuarine animals. - Mar. Biol. Lett. 2, 107-121.

Truchot, J. P., 1979. Mechanisms of the compensation of blood respiratory acid-base disturbances in the shore crab, Carcinus maenas (L.). - J. exp. Zool. 210, 407-416.

Wharton, D.C. \& Tzagoloff, A., 1967. Cytochrome oxidase from beef heart mitochondria. - Meth. Enzym. 10, 245-250. 